\title{
Post-Buckled Precompressed (PBP) piezoelectric actuators for UAV flight control
}

\author{
Roelof $\operatorname{Vos}^{a}$ Ron Barrett ${ }^{b}$ Lars Krakers $^{a}$ and Michel van Tooren ${ }^{a}$ \\ ${ }^{a}$ Faculty of Aerospace Engineering, Delft University of Technology, Delft, The Netherlands \\ ${ }^{b}$ Department of Aerospace Engineering, The University of Kansas, Lawrence, KS, USA
}

\begin{abstract}
This paper presents the use of a new class of flight control actuators employing Post-Buckled Precompressed (PBP) piezoelectric elements in morphing wing Uninhabited Aerial Vehicles (UAVs). The new actuator relies on axial compression to amplify deflections and control forces simultaneously. Two designs employing morphing wing panels based on PBP actuators were conceived. One design employed PBP actuators in a membrane wing panel over the aft $60 \%$ of the chord to impose roll control on a $720 \mathrm{~mm}$ span subscale UAV. This design relied on a change in curvature of the actuators to control the camber of the airfoil. Axial compression of the actuators was ensured by means of rubber bands and increased end rotation levels with almost a factor of two up to $\pm 13.6^{\circ}$ peak-to-peak, with excellent correlation between theory and experiment. Wind tunnel tests quantitatively proved that wing morphing induced roll acceleration levels in excess of $1500 \mathrm{deg} / \mathrm{s}^{2}$. A second design employed PBP actuators in a wing panel with significant thickness, relying on a highly compliant Latex skin to allow for shape deformation and at the same time induce an axial force on the actuators. Bench tests showed that due to the axial compression provided by the skin end rotations were increased with more than a factor of two up to $\pm 15.8^{\circ}$ peak-to-peak up to a break frequency of $34 \mathrm{~Hz}$. Compared to conventional electromechanical servoactuaters, the PBP actuators showed a net reduction in flight control system weight, slop and power consumption for minimal part count. Both morphing wing concepts showed that PBP piezoelectric actuators have significant benefits over conventional actuators and can be successfully applied to induce aircraft control.
\end{abstract}

Keywords: Piezoelectric, Flight Control, Morphing Wing, Post-Buckled Precompressed, UAV

\section{NOMENCLATURE}

\begin{tabular}{lll} 
Symbol & Description & Units \\
$A, B, D$ & in-plane, coupled, bending laminate stiffnesses & $\mathrm{N} / \mathrm{m}, \mathrm{N}, \mathrm{Nm}$ \\
$b$ & Span & $\mathrm{m}$ \\
$c$ & Chord & $\mathrm{m}$ \\
$C_{l}$ & Rolling moment coefficient & - \\
$F_{0}$ & Precompression force & $\mathrm{N} / \mathrm{m}$ \\
$f$ & Frequency & $\mathrm{Hz}$ \\
$I_{y}$ & Roll moment of inertia & $\mathrm{kgm}$ \\
$K$ & Structural stiffness & $\mathrm{N} / \mathrm{m}^{2}$ \\
$L$ & Actuator length & $\mathrm{m}$ \\
$M$ & Applied moment vector & $\mathrm{Nm} / \mathrm{m}$ \\
$N$ & Applied force vector & $\mathrm{N} / \mathrm{m}$ \\
$\dot{p}$ & Roll acceleration & $\mathrm{deg} / \mathrm{s}^{2}$ \\
$S$ & Wing reference surface area & $\mathrm{m}^{2}$ \\
$t$ & Thickness & $\mathrm{m}$ \\
$\alpha$ & Angle of attack & $\mathrm{deg}$ \\
$\delta$ & PBP beam angle & $\mathrm{deg}$ \\
$\delta_{0}$ & PBP end deflection & $\mathrm{deg}$ \\
\hline
\end{tabular}

Send correspondence to Roelof Vos

E-mail: roelof_vos@hotmail.com

Smart Structures and Materials 2006: Smart Structures and Integrated Systems,

edited by Yuji Matsuzaki, Proc. of SPIE Vol. 6173, 61730E, (2006) · 0277-786X/06/\$15

doi: $10.1117 / 12.658695$

Proc. of SPIE Vol. 6173 61730E-1 
$\theta$

$\Theta$

$\kappa$

$\Lambda$

$\rho$

$\sigma$
PBP end rotation angle

Normalized PBP end rotation angle

Curvature

Unloaded actuator strain

Density

Normal stress deg

$1 /$ deg

$-$

$\mathrm{kg} / \mathrm{m}^{3}$

$N / m^{2}$

Subscripts
$a$
$b$
$l$
$s p$
$t$

Actuator
Bonding layer
laminate
Negative spring rate
Thermal

\author{
Abbreviations \\ CAP Conventionally Attached Piezoelectric \\ CLPT Classical Laminated Plate Theory \\ LNPS Low Net Passive Stiffness \\ PBP Post-Buckled Precompressed \\ PZT Lead Titanate Zincronate \\ UAV Uninhabited Aerial Vehicle \\ ZNPS Zero Net Passive Stiffness
}

\section{INTRODUCTION}

For almost a century, piezoelectric materials have been successfully applied in various products (e.g. Sonar sensors, stereo tweeters, helicopter blade elements) using piezoelectric sheets, stacks and blocks as driving elements. ${ }^{1}$ Numerous studies have been focused on the addition of various types of mechanisms, the use of different lamination techniques and/or shapes to amplify either force at the expense of deflection or deflection at the expense of force. ${ }^{2-5}$ Although often effective, each of these mechanisms increased the complexity of the structure and often came with a significant weight penalty.

Since the beginning of the 1990's, piezoelectric materials have been successfully used to enhance flight control on small Uninhabited Aerial Vehicles (UAVs). Ranging from twist active wings to solid state adaptive rotors, each of these applications has been demonstrated on the bench, in the wind tunnel and eventually in flight. ${ }^{6-9}$ Overall benefits of using piezoelectric actuators over conventional actuators were proven substantial: reduction in weight, power consumption and part-count while increasing accuracy and break frequency. ${ }^{10}$

Recent improvements of the traditional piezoelectric bender elements have added to these advantages. For equal force levels, deflections can be increased with a factor of four with respect to conventional actuators. ${ }^{11}$ This implies that the total work of the actuators is increased significantly without violating any of the aforementioned benefits. This new class of actuators employ Post-Buckled Precompressed (PBP) piezoelectric elements and were demonstrated in flight, controlling grid fins on the XQ-138, a subscale Coleopter. Switching from conventional electromechanical actuators to PBP actuators led to an overall performance enhancement for this aircraft. ${ }^{11,12}$

The fundamental difference between the conventional piezoelectric bender elements and the PBP elements is found in the inherent stiffness of the actuator. The force produced by a conventional piezoelectric actuator is balanced by the product of its stiffness and the stroke: $F_{\text {piezo }}=K \Delta x$. Where a relative small $F_{\text {piezo }}$ fights against a relative large $K$, producing a stroke, $\Delta x$. A negative spring rate mechanism, $K_{s p}$, can be used to decrease the stiffness of the actuator. Consequently, for the same force, higher deflections can be achieved: $F_{\text {piezo }}=\left(K-K_{s p}\right) \Delta x$. When $K_{s p}$ approaches $K$, the structure will have a Low Net Passive Stiffness (LNPS) or even Zero Net Passive Stiffness (ZNPS). It are these principles that led to an increase in actuator stroke up to $300 \% .11,13$

The negative spring rate mechanism that was used consisted of an axial force, loading the bimorph bender element in compression. Any initial bending imperfection in the laminate, induced by the piezoelectric elements, was magnified by this compressive force, leading to the desired increase in deflection. This same principle made it possible to integrate these actuators in a deformable wing structure. 


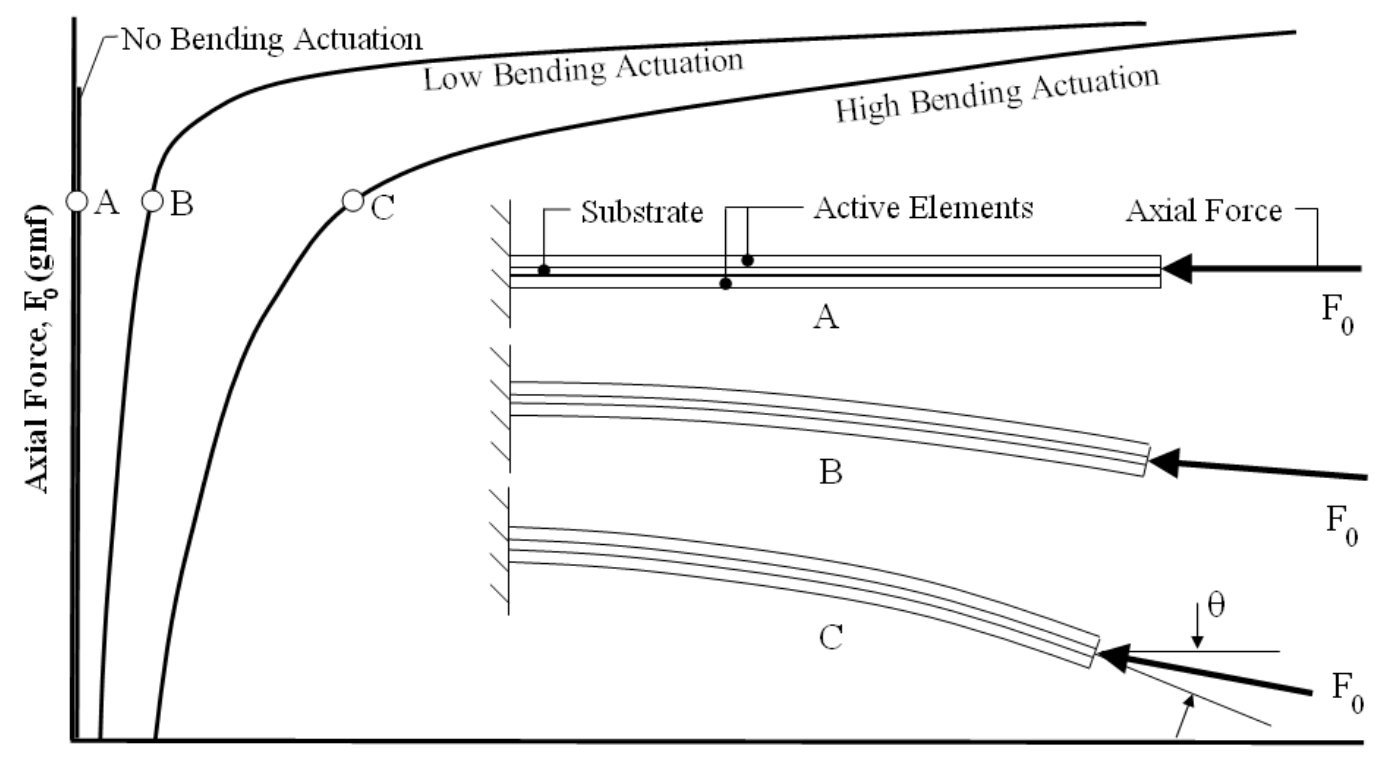

End Rotation, $\theta(\mathrm{deg})$

Figure 1. Cantilevered Actuator Arrangement for the Post-Buckled Precompressed Element

\section{ANALYTIC MODELING}

As was shown by Lesieutre, by applying a compressive force to a piezoelectric bender element, the conversion efficiency from electrical energy to mechanical work can be higher for the structure than the conversion efficiency of the material itself. ${ }^{14,15}$ To take advantage of the high deflections of the PBP actuator, a bender element was arranged in a cantilevered configuration with an external axial load applied at the tip of the actuator. As can be seen in Figure 1 the maximum axial force on the actuator is limited by tensile and compressive depoling and mechanical failure limits on the actuator sheets as the perfect buckling load is approached. When the axial force approaches the buckling load, the amplification ratio increases exponentially. Especially at high bending actuation, deflection levels can be increased up to a factor of four. ${ }^{11}$ However, care is needed to prevent the convex actuator surface from various forms of tensile failure, including depoling and mechanical fracture.

The unloaded actuator $\left(F_{0}=0\right)$ can be modeled using Classical Laminated Plate Theory (CLPT) methods. ${ }^{16}$ Actuator in-plane forces and moments $(a)$ are balanced by external forces and moments $(e x)$ and forces and moments due to a mismatch in coefficients of thermal expansion $(t)$. These forces and moments will generate strains, $\epsilon$, and curvatures, $\kappa$, in the laminate $(l)$ :

$$
\left(\begin{array}{l}
N \\
M
\end{array}\right)_{a}+\left(\begin{array}{l}
N \\
M
\end{array}\right)_{e x}+\left(\begin{array}{c}
N \\
M
\end{array}\right)_{t}=\left[\begin{array}{cc}
A & B \\
B & D
\end{array}\right]_{l}\left(\begin{array}{c}
\epsilon \\
\kappa
\end{array}\right)_{l}
$$

For a bender element which is symmetric in both material properties as in geometry the amount of curvature, $\kappa$, is independent of the thermally induced stresses. Since in-plane strains due to thermally induced stresses are balanced across the neutral axis, this term is neglected as they do not influence bending deflections. The forces and moments in the laminate that are induced by the actuator elements are a function of the piezoelectric virgin strain, $\Lambda$. Assuming no external loading, equation 1 can be written as:

$$
\kappa=\frac{B_{a}}{D_{l}} \Lambda
$$

By using the initial curvature, $\kappa$, as a starting point, the relation between the end rotation, $\theta$, of the actuator and the precompression force can be derived. Figure 2 shows the cantilevered actuator setup. The angular 


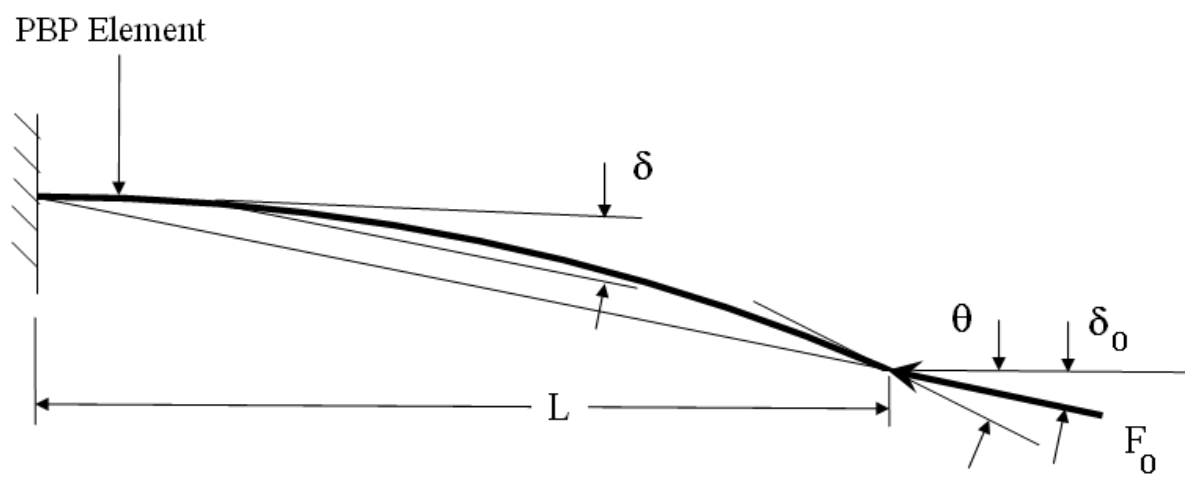

Figure 2. Cantilevered Actuator Arrangement for the Post-Buckled Precompressed Element

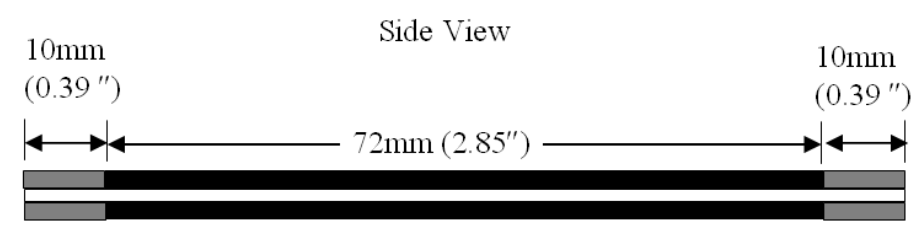

$191 \mu \mathrm{m}(7.5 \mathrm{mil})$ thick PZT-5A piezoceramic sheets

$76 \mu \mathrm{m}$ (3mil) thick aluminum substrate, $31 \mu \mathrm{m}$ (1.2 mil) bond on either side

$191 \mu \mathrm{m}$ (7.5mil) Glass Fiber Reinforced Plastic end tabs

Figure 3. PBP Actuator Geometry and Constituents.

coordinate, $\delta$, is maximized at the ends of the element, $\delta_{0}$, and goes to zero at the mid point. The end rotation is determined to be $\theta=2 \delta_{0}$. For this cantilevered $\mathrm{PBP}$ actuator lay-out the following relation between the end-rotation, initial curvature and axial force, $F_{0}$, was found: ${ }^{11}$

$$
\frac{L}{2} \sqrt{\frac{F_{0}}{D b}}=\int_{0}^{\frac{\pi}{2}} \frac{\sin \left(\frac{\theta}{4}\right) \cos \xi}{\left(\sqrt{\sin ^{2}\left(\frac{\theta}{4}\right) \cos ^{2} \xi+\frac{\kappa^{2} D b}{4 F_{0}}}\right)\left(\sqrt{1-\sin ^{2}\left(\frac{\theta}{4}\right) \sin ^{2} \xi}\right)} d \xi
$$

where $\xi$ is related to $\delta$ via:

$$
\xi=\sin ^{-1}\left(\frac{\sin (\delta / 2)}{\sin (\theta / 4)}\right)
$$

\section{MORPHING WING DESIGN, MANUFACTURING AND TESTING}

\subsection{Actuator Design}

The cantilevered PBP actuator was integrated in two distinct morphing wing designs. Sections 3.2 and 3.3 will elaborate on these two designs and show how this compressive force is applied. Although these designs differed in both shape and dimension, the actuator elements had an identical composition. As is shown in Figure 3 the PBP actuators were based on Conventionally Attached Piezoelectric (CAP) bender actuators. The actuator consisted of two identically poled PZT 5A sheets that were bonded on either side of a full-hard AISI 1018 aluminum substrate. To protect the actuator, end tabs consisting of a Glass fiber mesh in an Epoxy matrix were bonded to the substrate. 


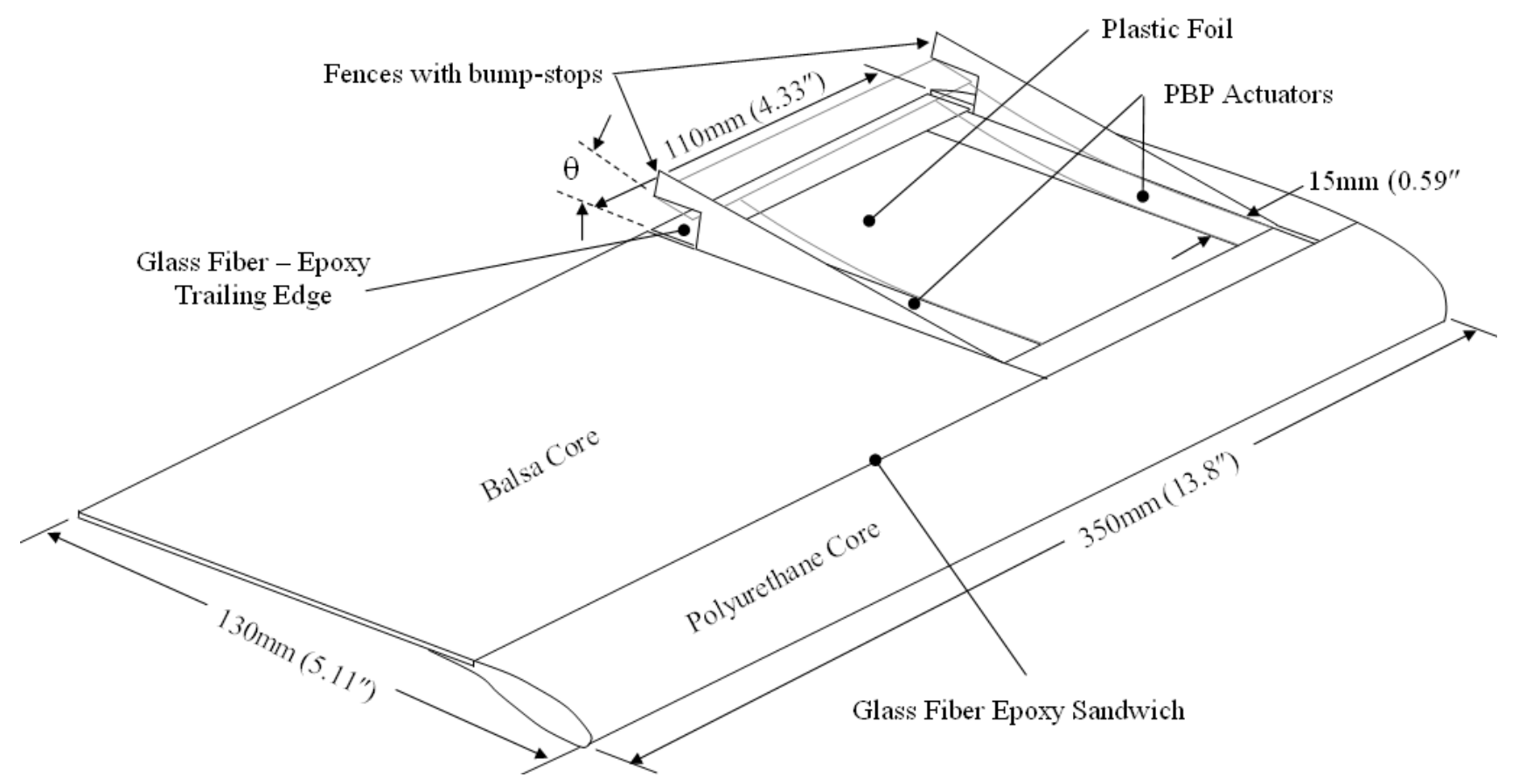

Figure 4. Design of Left Wing with Morphing Panel for Roll Control

To decrease the chance of mechanical fracture in the convex actuator a classical technique was used to precompress the tension-sensitive piezoelectric elements. Cured at elevated temperatures ( $\mathrm{T}=150 \mathrm{deg}$. C), the mismatch in coefficient of thermal expansion (CTE) between the Aluminum substrate and the PZT sheets induced precompression in the piezoelectric elements and pretension in the Aluminum substrates. ${ }^{17}$ The precompression in the piezoelectric elements ensured that even at high curvatures the convex face would still remain in compression.

\subsection{Membrane Morphing Wing}

Using the change in curvature of the actuator itself, a simple morphing wing panel could be constructed. In place of ailerons, a design incorporating morphing panels was made for a subscale UAV with a wing span of $720 \mathrm{~mm}$ (28.3"). The design of this wing basically consisted of an aerodynamically shaped leading edge over the first $30 \%$ of the chord, with a thin flat plate behind it that covered the aft $70 \%$ of the chord. Between $62 \%$ to $94 \%$ of the semi-span of the wing, this flat plate could be curved over the aft $60 \%$ of the chord by two PBP actuators which each measured 15mm (0.59") in width. Figure 4 shows the design of the left wing, including the morphing panel. To induce the axial compression, rubber bands were positioned over the actuators. By controlling the curvature of the flat plate, the camber of the airfoil could be changed and with that the local lift coefficient.

To be able to accurately measure the influence of wing deformation in the wind tunnel, the non-deforming part of the wing had to possess a high stiffness. To this extent, a sandwich construction of the wing was made. As a core material a un-curved Balsa wood sheet (thickness 1mm) was used for the flat rear part, while polyurethane foam was used for the leading edge. Before they were covered with glass fiber cloth, both the left and the right wing were joined and a dihedral of $2^{\circ}$ was imparted. The wing fences, which were designed to protect the morphing wing panels from over-rotating were also covered with glass fiber and everything was impregnated as a whole.

To demonstrate the advantages of axial compression on the piezoelectric actuators, a static bench test was carried out. The test set-up consisted of a Neon-Helium laser which reflected off a miniature mirror attached to the trailing edge of the panel and projected onto a screen. The end rotation of the trailing edge, $\theta$, was measured up to a tenth of a degree of accuracy. A static voltage sweep was carried out ranging from $-100 \mathrm{~V}$ to $+100 \mathrm{~V}$ at 


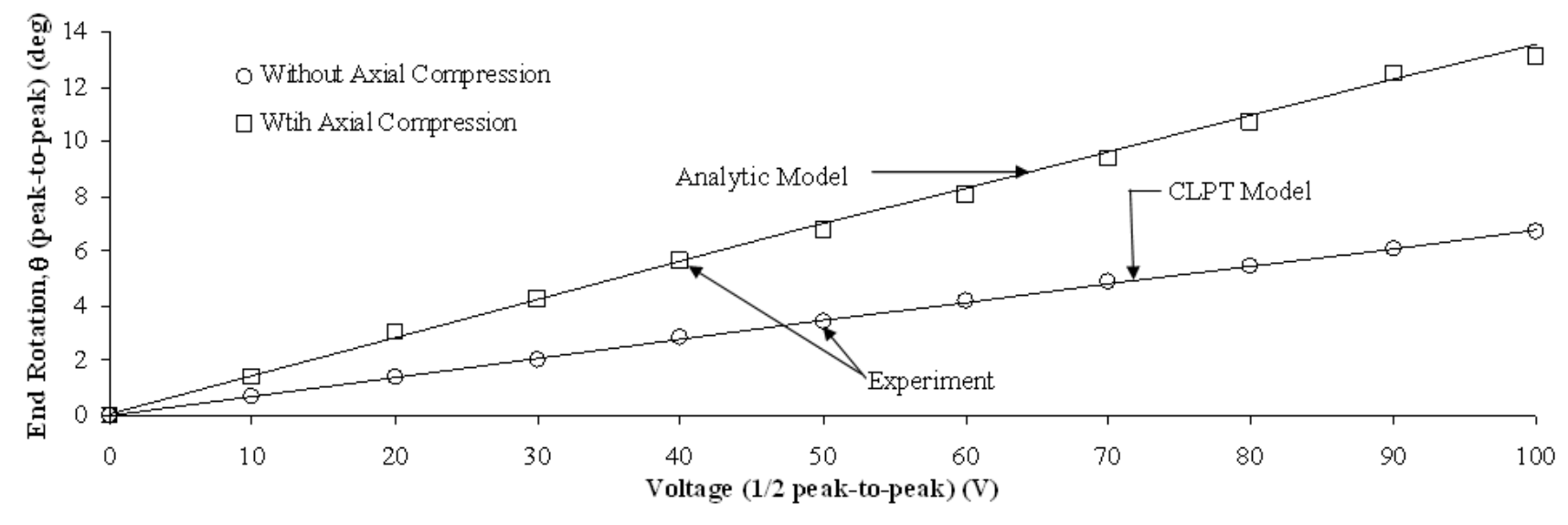

Figure 5. Relation Between Voltage, V, and End Rotation, $\theta$ for Free Actuators and Axially Compressed Actuators.

steps of 10V. First the "free deflection" was measured, implying no axial force was applied. Then, an axial force of $800 \mathrm{gmf}$ per actuator was applied by the rubber bands. The experiment was repeated and the end rotations were recorded again. Figure 5 displays the peak-to-peak end rotations of the morphing panels, induced by the PBP actuators as a function of voltage.

From the graph in Figure 5 it can be seen that an axial precompression of $53 \mathrm{gmf} / \mathrm{mm}$ of actuator width increased the amount of end rotation with almost a factor of 2 up to $13.6^{\circ}$ peak-to-peak. Furthermore, it can be seen that the analytical model that was originally developed to predict end-rotations for pin-pin configured PBP elements gives an accurate estimation of the end rotation of the cantilevered PBP elements.

Following static bench tests, wing and fuselage were assembled in order to determine the aircraft's controllability during wind tunnel tests. Marginal adjustments to the wing were needed in order to attach the wind tunnel supports. To be able to record the end rotations of the morphing panels during wind tunnel tests, each panel was equipped with two strain gauges on the bottom side of the inboard PBP actuator. Strains could be recorded during the wind tunnel experiment without interfering with the flow field. The strain, $\epsilon_{a}$, on the face of the piezoelectric sheet could be directly translated to the end rotation, $\theta$, of the morphing panels:

$$
\theta=\kappa \cdot L=\frac{2 \epsilon_{a}}{t} \cdot L
$$

where, $L$ was the unstrained length of the actuator and amounted to $72.4 \mathrm{~mm}(2.85 ")$ and $t=0.52 \mathrm{~mm}$ was the thickness of the laminate.

In addition, the voltage of over the piezoelectric elements could be remotely controlled. An electronic circuit was designed in order to make the piezoelectric elements compatible with standard remotely controlled aircraft electronics. The electronic circuit consisted of three major components: a servo controller, which altered the pulsewidth modulated signal to a direct current signal, a dual direct current converter (PICO 5A48D), which converted the $5 \mathrm{~V}$ feed current to $95 \mathrm{~V}$, and two OPA445 high voltage op-amps to amplify the control signal to voltage levels up to $\pm 95 \mathrm{~V}$. The total electronic circuit weighed 22 grams. However, it was estimated that by further miniaturization of the servo controller and the op-amps total electronics weight could be decreased to 5 grams.

Figure 6 shows the aircraft (a) and the wind tunnel setup (b). The aircraft was tested in the Low Speed Wind Tunnel at Delft University of Technology. The cruise velocity for this aircraft was estimated to be $25 \mathrm{~m} / \mathrm{s}$. At this velocity, the optimum flight condition for maximum range (i.e. maximum L/D) occurred at an angle of attack of $8^{\circ}$. At this point a sweep was carried out, steering the aircraft from left to right and back to the left. Both the end rotation, $\theta$ of the PBP actuators and the Rolling Moment Coefficient, $C_{l}$, were recorded simultaneously. 

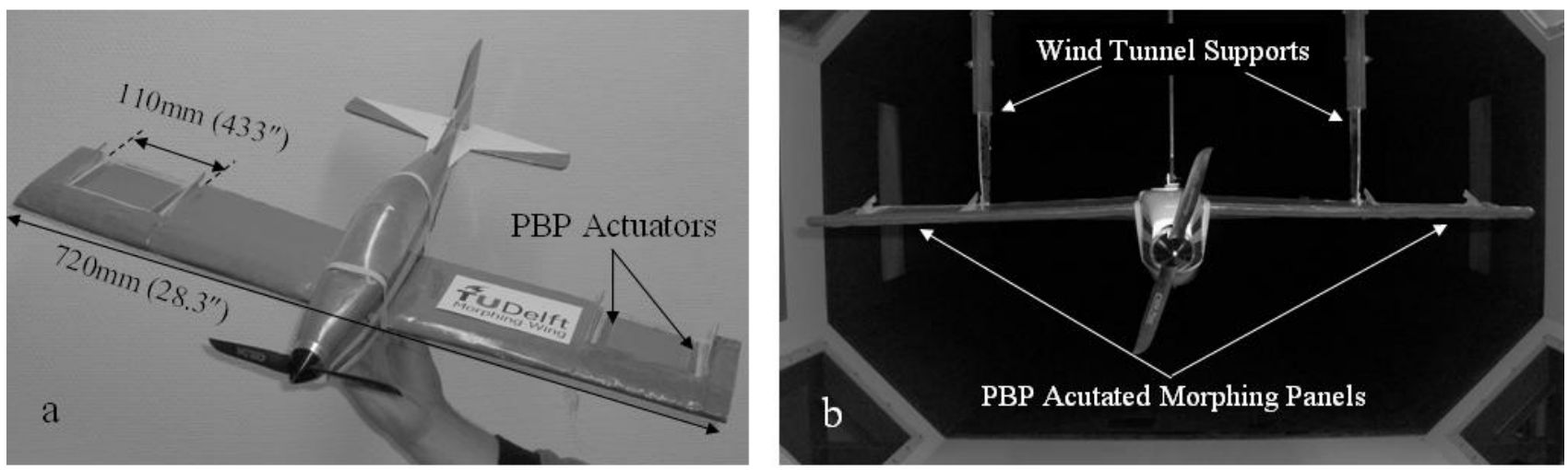

Figure 6. Subscale UAV with Modified Wing Including PBP Morphing Panels for Roll Control (a), and Wind Tunnel Setup (b).

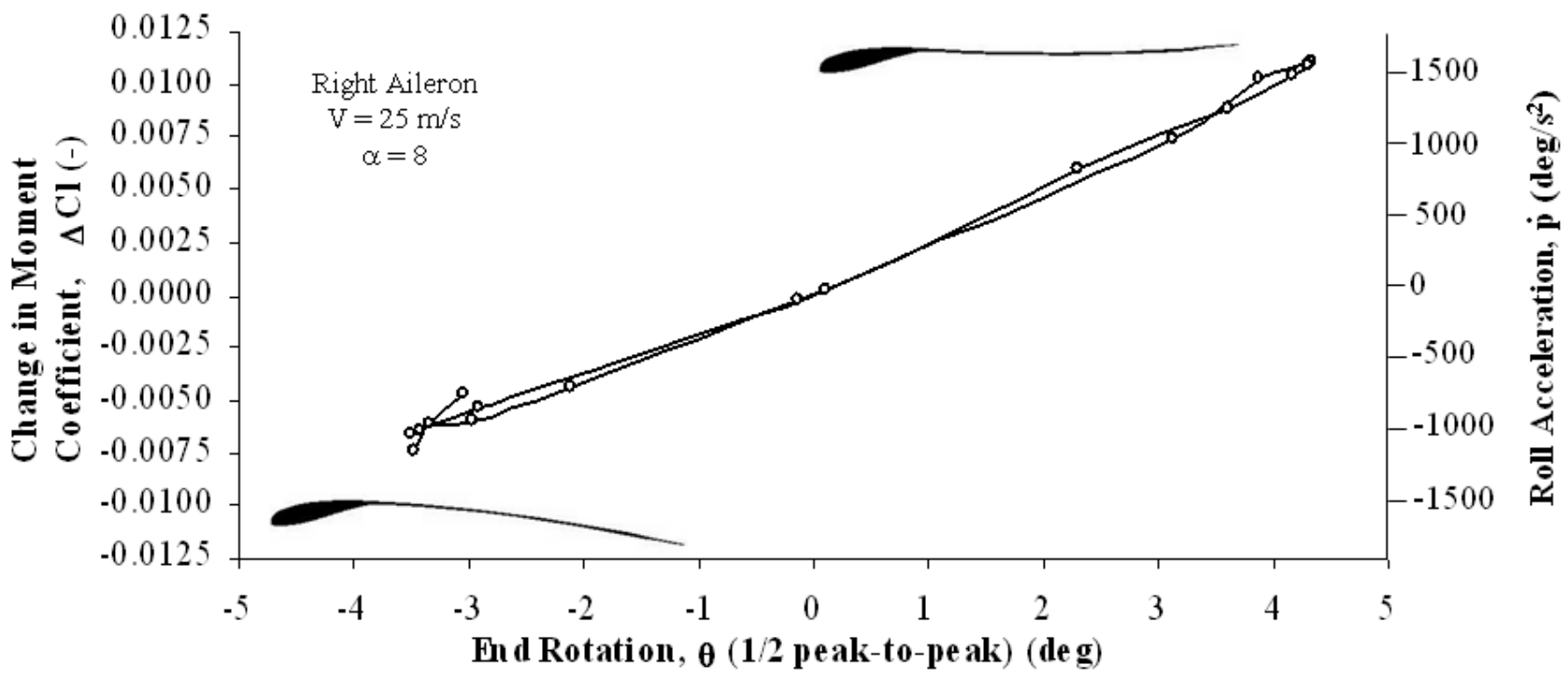

Figure 7. Relation Between PBP End Rotation, $\theta$, the change in Rolling Moment Coefficient, $\Delta C_{l}$ and Roll Acceleration, $\dot{p}$.

The roll acceleration, $\dot{p}$, that was induced by the rolling moment can be calculated using:

$$
\dot{p}=\frac{C_{l} \frac{1}{2} \rho V^{2} S b}{I_{y}}
$$

where, $I_{y}$ is the aircraft's moment of inertia about its longitudinal axis, $S$ is the wing reference surface area $\left(S=0.0936 \mathrm{~m}^{2}\right.$ and $\rho$ is the density of the air $\left(\rho=1.248 \mathrm{~kg} / \mathrm{m}^{3}\right)$. A simplified model of the aircraft was used to calculate its moment of inertia. It was assumed that the wing weight $(0.225 \mathrm{~kg})$ was distributed uniformly over the span of the wing. Furthermore it was assumed that the fuselage weight $(0.343 \mathrm{~kg})$ was uniformly distributed over a circular cross section with a radius of $40 \mathrm{~mm}$. This resulted in a total moment of inertia for this aircraft of $I_{y}=0.00999 \mathrm{kgm}^{2}$. Figure 7 shows the relation between the end rotation of the right morphing panel and the induced roll acceleration.

From Figure7 it can be seen that roll accelerations in excess of $1500 \mathrm{deg} / \mathrm{s}^{2}$ could be obtained by deforming the panels. Furthermore, a linear relationship was demonstrated between the roll acceleration and end-rotation 


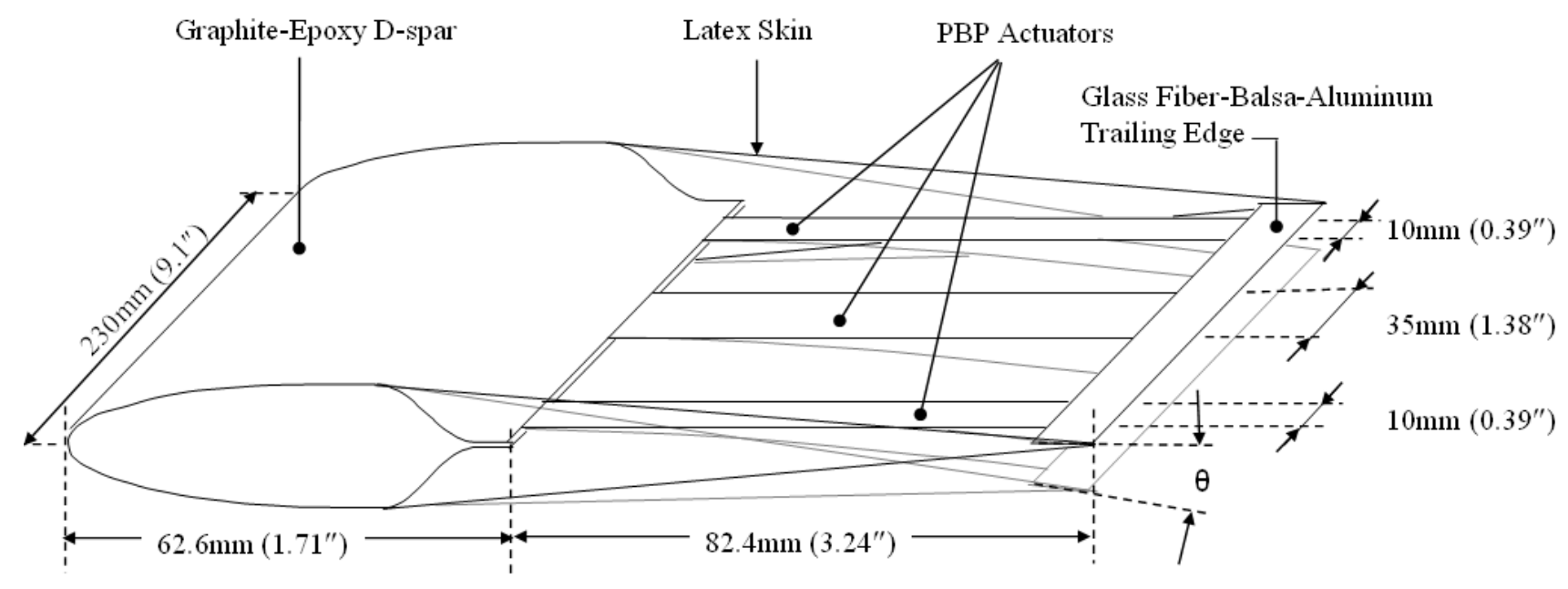

Figure 8. Morphing Wing Actuator Geometry

of the panel. From the slope of the $C_{l}-\theta$ line the control derivative $\Delta C_{l_{\delta}}$ can be determined, which is a measure for the effectiveness of aileron deflection. Keeping in mind that the end rotation, $\theta$, equals twice the trailing edge deflection, $\delta_{0}$, the derivative of the rolling moment to trailing edge deflection can be expressed as:

$$
C_{l_{\delta}}=\frac{2 \Delta C_{l}}{\Delta \theta}=0.0047[1 / \mathrm{deg}]
$$

\subsection{Thick Airfoil Morphing Wing}

In order to explore the use of PBP actuators in wings with a significant thickness, a design was made to supply a $1.4 \mathrm{~m}$ (55") span subscale UAVs with two morphing panels based on the PBP actuators. The wing was designed to be straight (no sweep or taper) and with a dihedral of $2^{\circ}$. Each of the morphing panels measured $230 \mathrm{~mm}$ (9.1") in span 145mm (4.95") in chord and were positioned at the most outboard positions of the wing.

In order to make the airfoil deform upon actuation, a thin latex skin was applied that covered the entire perimeter of the airfoil. The latex skin acted as an aerodynamic surface and at the same time as a (non-linear) spring that compressed the PBP actuators. To achieve perfect axial compression in the piezoelectric actuators, it was determined that the airfoil shape needed to be symmetrical and was therefore based on a NACA 0012 airfoil. The maximum thickness of the profile measured $12 \%$ of the chord length and was situated at $30 \%$ of the chord length, measured from the leading edge.

The structure for this morphing wing panel consisted of a Graphite-Epoxy D-spar that dictated the shape over the first 30\% of the airfoil. Between this D-spar ( $40 \%$ chord) and a composite trailing edge strip (98\% chord), three PBP actuators were positioned. The taut latex skin was supported at the trailing edge of the airfoil and at the thickest point of the D-spar. This allowed for vertical travel of the skin without being restrained by the wing structure. As can be seen in Figure 8, by activating the PBP actuators their curvature could be changed. Although the PBP actuators themselves only spanned half of the wing chord, due to the taut skin $70 \%$ of the wing chord could be deformed upon actuation.

To measure the end rotations of the morphing wing, a test article was made. The test article had the same chord length $(145 \mathrm{~mm})$ as the designed panel, however it spanned only $100 \mathrm{~mm}(0.39 ")$. Two actuators of each $15 \mathrm{~mm}(0.59 ")$ in width were used to induce wing morphing. The ratio between actuator width and skin width was identical for both the test article and the designed morphing panel as presented in Figure 8. The latex skin over the PBP actuators supplied the two actuators with an axial compressive force of $70.7 \mathrm{gmf} / \mathrm{mm}$ actuator 


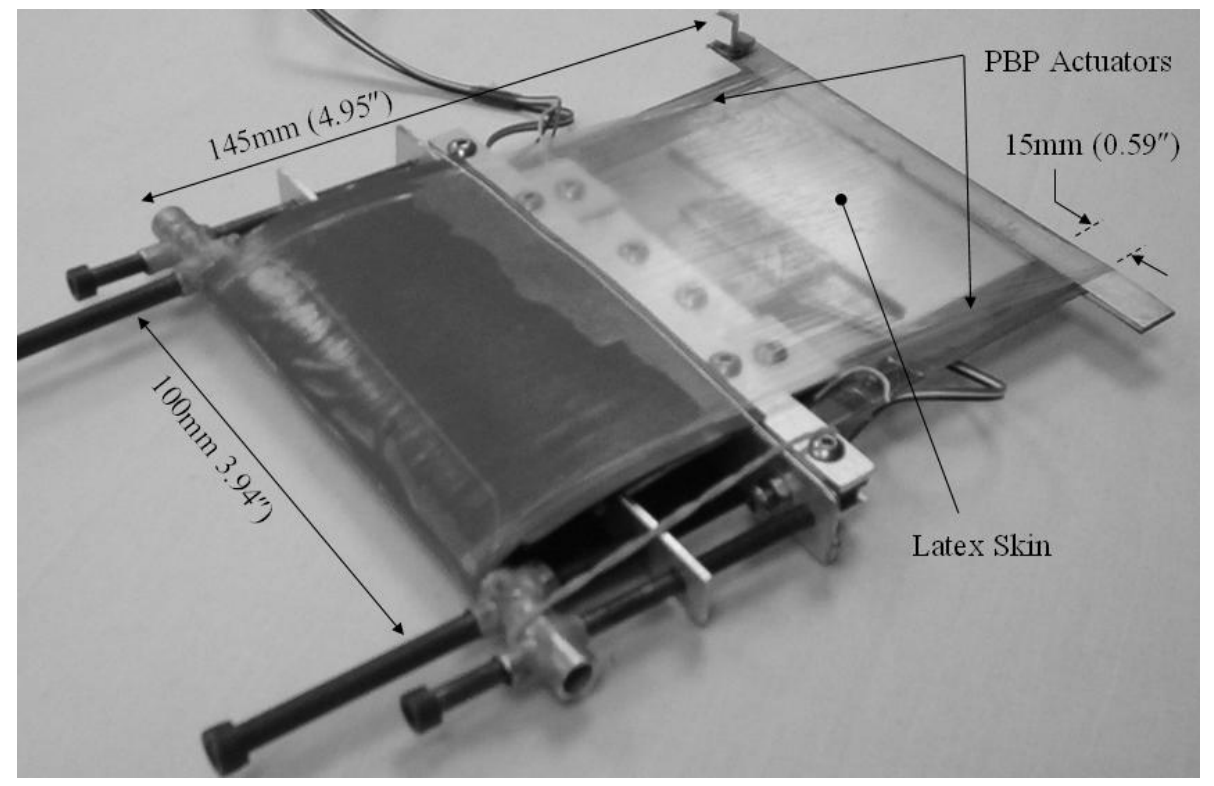

Figure 9. PBP Bench Test Article.
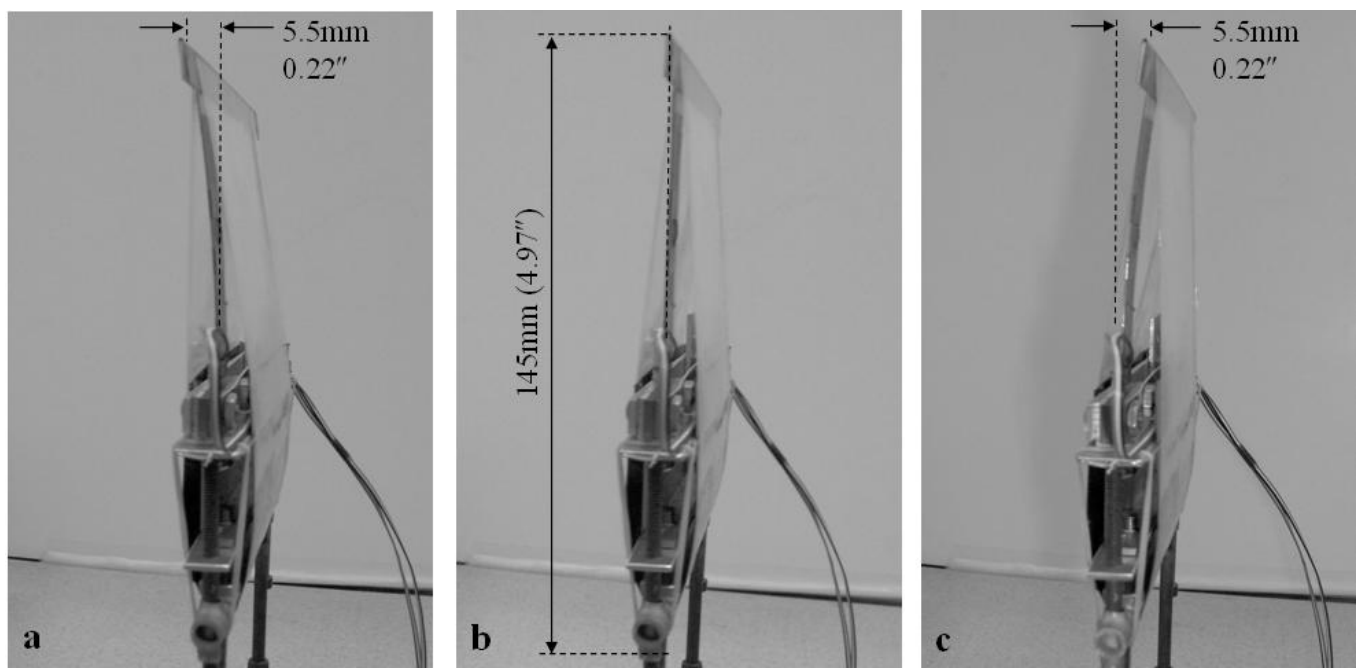

Figure 10. PBP Bench Test Article Deflections. 



Figure 11. Results of Static (a) and Dynamic (b) Bench Tests.

width. As can be seen in Figure 10, the outer airfoil shape changed substantially when the PBP actuators are being curved.

Measurements of end rotations were taken using laser reflection off the trailing edge of the test article. Without the skin, the end rotations measured $7^{\circ}$ peak-to-peak. By applying the latex skin to compress the actuators, the end rotations more than doubled to $15^{\circ}$ peak-to-peak (see Figure 11-a).

In addition to the quasi static bench test a frequency sweep test was carried out where trailing edge end rotations were recorded and normalized with respect to the quasi static end rotations (see Figure 11-b). Without the skin applied, the natural frequency of the actuators measured $31 \mathrm{~Hz}$. The application of the skin shifted the natural frequency back to $26 \mathrm{~Hz}$. The corner frequency of this system amounted to $34 \mathrm{~Hz}$.

The PBP actuated morphing panels were integrated into a wing which was specially made to host these panels. The static part of the wing was based on a NACA 0012 airfoil and its structure consisted of Balsa wood ribs and spars. To prevent the actuators from over-rotating during flight, fences were placed at either side of the panels. A cut-out at the rear of each of the fences allowed the trailing edge of the morphing panel to travel a a maximum of $20 \mathrm{~mm}(0.79 ")$ peak-to-peak in vertical direction. At the outboard sides of the wing the fences simultaneously acted as winglets that protected the morphing panel during a heavy landing. Figure 12-a shows the entire aircraft with the morphing panels at the outboard sides of the morphing wing.

To show that the morphing wing panels could successfully be used to control the aircraft during flight, a flight test was conducted. The test was carried out on 29 April 2005 in Auburn, Alabama under light and variable 5 kt winds, 15deg. C (59 deg. F) and 7 statute miles of visibility. Flight test showed excellent roll control. Figure 12-b shows the aircraft just after take-off.

\section{INTEGRATION AND COMPARISON}

Significant benefits were obtained by switching from a conventional aileron actuated wing to a PBP controlled morphing wing. Both morphing wing designs did not employ any linkages, gears, or heavy motors, and were therefore significantly lighter and less complex then electromechanical servoactuators. Since the PBP actuators operated under a high voltage but very low current, power consumption was decreased substantially. ${ }^{18}$ This in turn could lead to a reduction in battery capacity and consequently battery weight. Contradictory to conventional servoactuators, the PBP actuators were solid state, so part count, slop and deadband were one to two orders of magnitude lower. ${ }^{11}$ 

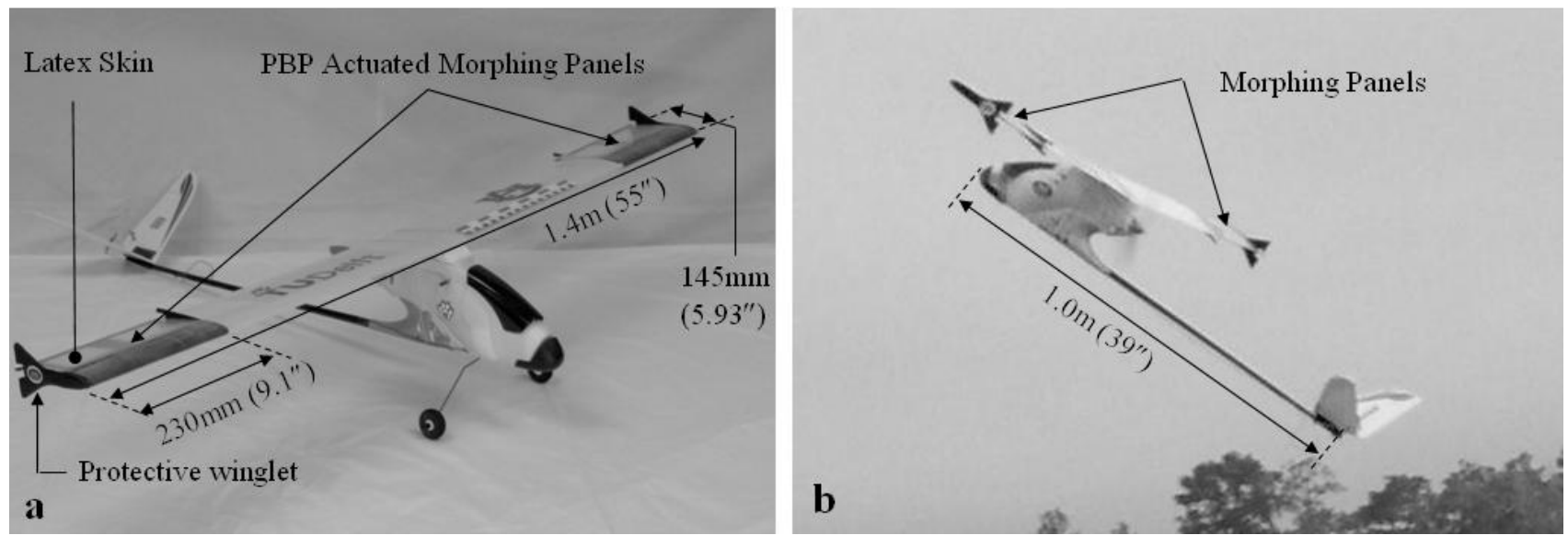

Figure 12. Morphing Wing UAV Lay-out (a) and Flight Test (b)

For the thick morphing wing a comparison was made between a conventional electromechanical actuator controlling two ailerons on a $1.4 \mathrm{~m}$ span UAV and the PBP actuators controlling the morphing wing panels. Table 1 shows how these two different actuators compare to each other.

Table 1. Comparison of Electromechanical Servoactuator and PBP Actuator

\begin{tabular}{lcc}
\hline & Conventional Servoactuator & PBP Actuator \\
\hline \hline Max Power & $24 W$ & $100 \mathrm{~mW}$ \\
Max Current & $5 \mathrm{~A}$ & $1.4 \mathrm{~mA}$ \\
Mass & $59 \mathrm{~g}$ & $24 \mathrm{~g}$ \\
Slop & $1.6^{\circ}$ & $0.02^{\circ}$ \\
Corner Frequency & $3 \mathrm{~Hz}$ & $34 \mathrm{~Hz}$ \\
Part Count & 56 & 6 \\
\hline
\end{tabular}

\section{CONCLUSIONS}

It has been shown by two different designs that a PBP actuated morphing wing can be successfully applied to induce roll control on subscale UAVs. One design relied on the change in curvature of a flat membrane to induce a change in airfoil camber. Static bench test showed that by adding axial compression to the actuators, end rotations were increased by almost a factor of two up to $13.6^{\circ}$ peak-to-peak with excellent correlation between theory and experiment. Wind tunnel tests on this design proved quantitatively that wing morphing induced by the PBP actuators resulted in a change in roll acceleration levels in excess of $1500 \mathrm{deg} / \mathrm{s}^{2}$. A second design employed PBP actuators in a highly compliant wing structure with significant thickness. Precompression induced by a Latex skin ensured an increase in end rotation by more than $100 \%$ up to $15.8^{\circ}$ peak-to-peak. Free flight tests on a $1.4 \mathrm{~m}$ subscale uninhabited aircraft employing morphing wing panels in place of ailerons showed excellent roll control upon wing morphing. With respect to conventional electromechanical servoactuators, applying PBP actuators led to a saving in flight control system weight with $60 \%$ and an increase in break frequency from $3 \mathrm{~Hz}$ up to $34 \mathrm{~Hz}$. Moreover, switching to PBP actuators decreased current draw, power consumption, slop and part count by at least an order of magnitude.

\section{ACKNOWLEDGEMENTS}

This research was sponsored by the Aerospace Department of Auburn University, the Netherlands Institute for Metal Research (NIMR) and the Faculty of Aerospace Engineering of Delft University of Technology. The 
authors would like to thank Mr. Christoph Burger, Mr. Paolo Tiso, Mr. Roeland de Breuker, Mr. Rick Ruysink, Mr. Leo Molenwijk, Mr. Hans Weerheim, Dr. Mostafa Abdallah, Prof. Leo Veldhuis and Prof. Zafer Gurdal for their individual contributions to this project.

\section{REFERENCES}

1. Crawley, E., and Luis, J. D., "Use of piezoelectric actuators as elements of intelligent structures," AIAA Journal 25, pp. 987-997, October 1987.

2. Moskalik, A. J., and Brei, D., "Analytical dynamic performance modeling for individual c-block actuators," Journal of Vibrations and Acoustics 121, pp. 221-230, 1998.

3. Moskalik, A. and Brei, D., "Force-deflection behavior of piezoelectric c-block actuator arrays," Smart Materials and Structures 8, pp. 531-543, 1999.

4. Ervin, J. and Brei, D., "Recurve piezoelectric-strain-amplifying actuator architecture," EEE/ASME Transactions on Mechatronics 3(4), pp. 293-301, 1998.

5. Clement, J., Brei, D., Moskalik, A. and Barrett, R., "Bench-top performance characterization of a c-block driven active flap system," in proceedings of the 39th Structures, Structural Dynamics and Materials Conference 20 - 23 April 1998, (AIAA-98-2039), American Institute of Aeronautics and Astronautics, Washington, D.C., (Long Beach, CA), 1998.

6. Barrett, R., Gross, S. and Brozoski, F., "Design and testing of subsonic all-moving smart flight control surfaces," in Procedings of the 36th AIAA Structures, Structural Dynamics and Control Conference, pp. 22892296, (New Orleans, LA), April 1995.

7. Barrett, R., Gross, R. S. and Brozoski, F., "Missile flight control using active flexspar actuators," in Proceedings of the 1995 North American Conference on Smart Structures and Materials, pp. 52 - 61, (San Diego, CA), 26 Feb. - 3 Mar 1995.

8. Barrett, R., "Intelligent rotor blade and structures development using directionally attached piezoelectric crystals," Master's thesis, University of Maryland, College Park, MD, 1990.

9. Barrett, R. and Stutts, J., "Design and testing of a 1/12th scale solid state adaptive rotor," Journal of Smart Materials and Structures 6, pp. 491-497, August 1997.

10. Barrett, R. M., "Adaptive aerostructures: Improving high performance military subscale uavs," in Proceedings of the 45th AIAA/ASME/ASCE/AHS/ASC Structures, Structural Dynamics and Materials Conference, (Palm Springs, CA), 19 - 22 April 2004.

11. Barrett, R., McMurtry, R., Vos, R., Tiso, P. and De Breuker, R., "Post-buckled precompressed (pbp) elements: a new class of flight control actuators enhancing high speed autonomous vtol mavs," SPIE No. 5762-16, (San Diego), 6-10 March 2005.

12. Barrett, R., Vos, R., Tiso, P., and De Breuker, R., "Post-buckled precompressed (pbp) actuators: Enhancing vtol autonomous high speed mavs," in Proceedings of the 46th AIAA/ASME/ASCE/AHS/ASC Structures, Structural Dynamics and Materials Conference, (Austin, TX), 18-21 April 2005.

13. Barrett, R., and Tiso, P., "Post buckled precompressed actuator." International Patent Application PCT/NL2005/000054 by Delft University of Technology, 25 January 2005.

14. Lesieutre, G. and Davis, C., "Can a coupling coefficient of a piezoelectric acturato be higher than those of its active material?," Journal of Intelligent Materials Systems and Structures 8, pp. 859-867, 1997.

15. Lesieutre, G. and Davis, C., "Transfer having a coupling coefficient higher than its active material." U. S. Patent 6,236,143, May 2001.

16. Jones, R., Mechanics of Composite Materials, ch. Micromechanical Behavior of a Lamina. Hemisphere Publishing Cooporation, fourth si ed., 1975.

17. Barrett, R. M. and Stutts, J. C., "Development of a piezoceramic flight control surface actuator for highly compressed munitions," in Proceedings of the $39^{\text {th }}$ AIAA/ASME/ASCE/AHS/ASC Structures, Structural Dynamics, and Materials Conference, (Long Beach, CA), April 20-23 1998.

18. Bramlette, R., and Leurck, R., "A method for control surface deflection utilizing piezoceramic bimorph actuators," in proceedings of the $56^{\text {th }}$ AIAA Southeastern Regional Student Conference, (Gainesville, Florida), 4 April 2005. 